определения народов, он сказал, что в его представлении субъектами прав на самоопределение могут быть не только колониалыные народы, но и все народы вообще. Касаясь актуальной проблемы выполнения государствами их обязательств, связанных с этим правом народов, он сказал: “Мы ранее в Комитете 24-х, а теперь и в Суде сделали все, чтобы подтвердить его в качестве фундаментального принципа международного права. Теперь дело за самими субъектами этого права добиваться его реализации".

В целом же коллоквиум в Гааге показал, что, несмотря на объяснимую и, видимо, неизбежную консервативность любого судебного органа, Мехдународный Суд ООН, с одной стороны, находится под давлением процесса объективных изменений в мире за минувшие полвека, а с другой - в состоянии реагировать на них, адаптироваться и, следовательно, модернизироваться.

Это вселяет надежду на то, что практика и наука будут все чаще получать наиболее авторитетное подтверждение и развитие не только конвенционных основ, но и обычных норм международного права.

Москва - Гаага - Москва, апрель 19962.

\title{
ОБСУЖДЕНИЕ IІРОЕКТА УСТАВА МЕЖДУНАРОДНОГО УГОЛОВНОГО СУДА В СПЕЦИАЛЬНОМ КОМИТЕТЕ ГЕНЕРАЛЬНОЙ АССАМБЛЕИ ООН
}

В декабре 1996 года исполняется 50 лет с тех пор, как ООН приняла прннципы Нюрнбергского трибунала - прообраза Мөждународного уголовного суда. $И$ хотя он был трибуналом ad hос, төм не менөе его принципы легли в основу всөй послевоенной международной уголовной юстиции. Продолжая эту тему, МЖМП публикует настоящую статью.

История попыток создания постоянного органа международной уголовной юстиции насчитывает уже несколько десятилетий ${ }^{1}$. Впервые Организация Объединенных Наций обратилась $\mathbf{x}$ этой проблеме в 1948 году. Тогда стимулом для этого стало создание Нюрнбергского и Токийского трибуналов. Уже в начале 50-х годов появился первый проект Статута Международного уголовного суда. Однако работа над ним была прервана главным образом по политическим причинам. Поворотным моментом в истории создания постоянного Суда стало учреждение Советом Безопасности 
ООН двух трибуналов ad hoc - Международного трибунала для судебного преследования лиц, ответственных за серьезные нарушения международного гуманитарного права, совершенные на территории бывшей Югославии с 1991 года, и Международного уголовного трибунала для судебного преследования лиц, ответственных за геноцид и другие серьезные нарушения международного гуманитарного права, совершенные на территории Руаңды, и граждан Руанды, ответственных за геноцид и другие подобные нарушения, совершенные на территории соседних государств в период с 1 января 1993 г. по 31 декабря 1994 г.

В 1993 году Генеральная Ассамблея ООН предложила Комиссии международного права (далее - КМП) продолжить свою работу над составлением проекта Статута Международного уголовного суда с тем, чтобы выработать этот проект уже на сессии КМП 1994 года².

КМП представила такой проект 49-й сессии Генеральной Ассамблеи. При этом Комиссия рекомендовала Генеральной Ассамблее созвать международную конференцию для рассмотрения проекта Статута и принятия конвенции о создании Суда ${ }^{3}$.

Мнения государств в Генеральной Ассамблее относительно предложения КМП разделились. Большинство было готово поддержать рекомендацию Комиссии. Однако значительное число стран выразило сомнение относительно целесообразности поспешного принятия такого решения.

В этой ситуации Генеральной Ассамблеей было принято решение создать Специальный комитет для обзора основных вопросов существа и административных вопросов, вытекающих из проекта Статута, подготовленного КМП, и рассмотрения в свете такого ळбора вопроса о мероприятиях по созыву международной конференций.

В соответствии с принятым решением в 1995 году состоялись две сессии Спецкомитета. В основу дискуссии на сессиях был положен публикуемый ниже проект Статута Международного уголовного суда, подготовленный КМП. В результате его обсуждения наметились контуры будушего Суда. В то же время по ряду принципиальных положений продолжается острая дискуссия.

Наибольшие разногласия на сегодняшний день вызывает вопрос о предметной компетенции (или юрисдикции) Суда. Проект Статута, подготовленный КМП, основывался на том, что Суд должен обладать юрисдикцией в отношении двух категорий преступлений. Во-первых, это так называемые преступления по обшему международному праву, к которым относятся агрессия, геноцид, военные преступления и преступления против человечности. Во-вторых, так называемые договорные преступления, иначе говоря, преступления, квалифицируемые как таковые действующими универсальными международными договорами. В числе таких международных дого- 
воров: Женевские конденции 1949 года и Дополнительный протокол к ним, Конвенция о борьбе с незаконным захватом воздушных судов 1970 года, Конвенция о борьбе с незаконными актами, направленными против безопасности гражданской авиации 1971 года, Международная конвенция о пресечении преступлений апартеида и наказании за него 1973 года, Международная конвенция о борьбе с захватом заложников 1979 года и др.

Результатом работы Спецкомитета стал, по сушеству, консенсус относительно того, что юрисдикция Суда должна распространяться только на самые серьезные преступления по мехдународному праву, которые вызывают озабоченность мирового сообшества в целом ${ }^{5}$. Уже сейчас очевидно, что перечень преступлений первоначально будет ограничен тремя-пятью преступлениями. При этом Статут будет предусматривать механизм, предоставляющий государствам - участникам Статута возможность рассматривать на более позднем этапе вопрос о включении других преступлений ${ }^{6}$.

Необходимо отметить, что с точки зрения Комиссии Статут должен был стать чисто процессуальным документом. В нем не должны были содержаться определения преступлений, их составы. Однако государства почти единодушно решили по-другому. Осознавая предстоящие трудности в работе, они, тем не менее, договорились о том, чтобы включить в Статут квалификацию преступлений. Это, по их мнению, в наибольшей степени соответствовало бы принципу законности (nullum crimen sine lege). Именно это решение и предопределило разногласия в отношении преступлений по обшему международному праву.

Вопрос о включении в перечень преступлений геноцида практически не вызвал споров (ст. 20, П. $а$ проекта Статута). По мнению большинства делегаций, в Статуте следует использовать определение геноцида, содержащееся в Конвенции о предупреждении преступления геноцида и наказании за него 1948 года и в уставах югославского и руандийского трибуналов 7 .

Значительно больше трудностей вызвал вопрос о включении в перечень преступлений агрессии. Проект, подготовленный КМП, исходит из того, что «агрессия» является преступлением по общему международному праву. Именно поэтому преступление агрессии вошло в перечень преступлений, содержащийся в проекте Статута Суда, подготовленного КМП. В то же время еще в ходе подготовки проекта Статута высказывались сомнения относительно уместности включения в Статут агрессии. Ряд членов КМП уже на начальном этапе обозначили трудности, которые могут возникнуть в связи с включением этого преступления в проект. Подчеркивалось, что включение агрессии в Статут должно произойти лишь после того, как будет выработано ее обшеприемлемое определение ${ }^{8}$. Некото- 
рые члены КМП подвергди сомнению возможность индивидуальной ответственности за преступление агрессии, утверждая, что агрессия совершается только государствами.

Представители многих государств, принявшие участие в работе Спецкомитета, практически повторили уже ранее высказанные доводы против включения преступления агрессии в проект Статута. Помимо прочего, утверждалось, что определение агрессии, данное Геиеральной Ассамблеей в известной резолюции 3314 (1974), носит политический характер, адресовано исключительно Совету Безопасности и что международное право не предусматривает индивидуальной ответственности за агрессиюэ.

Кроме того, отмечалось, что даже если преступление агрессии и будет включено в перечень, то уж никак нельзя сохранить в Статуте роль Совета Безопасности ООН в отношении определения совершения агрессии государством как предварительного условия для рассмотрения Судом вопроса об уголовной ответственности индивида за агрессию ${ }^{10}$.

В то же время, как справедливо указывается в докладе КМП, «невключение агрессии в Статут Суда было бы шагом назад через 50 лет после приговора Нюрнбергского трибунала»". Комиссия сочла, что трудности определения и применения в сочетании с особой ответственностью Совета Безопасности по главе VII Устава, на основании положений которой Совет Безопасности уполномочен определять сушествование любой угрозы миру, любого нарушения мира или акта агрессии (ст. 39 Устава ООН), означают, что специальное положение для обеспечения возбуждения судебного преследования за агрессию необходимо предусмотреть лишь в том случае, если Совет Безопасности сначала выносит определение о том, что данное государство совершило акт агрессии в обстоятельствах, когда преступление агрессии является предметом обвинения ${ }^{12}$.

В поисках компромисса делегация России на второй сессии Спецкомитета предложила, чтобы в Статут Суда было включено не преступление агрессии как таковой, а - по аналогии с Уставом Нюрнбергского трибунала - планирование, подготовка, развязвание и ведение агрессивной войны. При этом российская делегация опиралась также на примерно такой же состав преступления, содержашийся в новом Уголовном кодексе Российской Федерации, принятом Государственной Думой и одобренном Советом Федерации.

Одновременно было предложено рассматривать вопрос о включении в Статут преступления агрессии в увязке с включением в него соответствующих полномочий Совета Безопасности на основании главы VII Устава ООН. Полномочия Совета Безопасности должны сохраняться в Статуте при том понимании, что квалифика- 
ция Советом Безопаснссти действий того или иного государства как агрессии не будет иметь преюдициального характера для последующего рассмотрения Судом вопроса об уголовной ответственности тех или иных лиц за подготовку, планирование, развязывание или ведение агрессивной войны. В то же время такое ретшение Совета Безопасности явилось бы необходимым процедурным условием для того, чтобы Суд мог рассматривать вопрос об индивидуальной уголовной ответственности за агрессивную войну (или arpecсию).

Большое внимание как КМП, так и Спецкомитет уделили серьезным нарушениям законов и обычаев, применимых в вооруженном конфликте (ст. 20, П.с проекта Статута). Проект КМП проводит различие между серьезными нарушениями закснпв и обычаев войны по обшему мехпународному праву и серьезными нарушениями Женевских конвенций 1949 года, которые были отнесены к разряду так называемых договорных преступлений. Данные две категории, по мнению КМП, пересекаются, однако они не идентичны. Тем не менее многие делегации в Спецкомитете предложили соединить эти две группы преступлений. Однако это не нашло поддержки у ряда делегаций, нашедших, что положения Женевских конвенций 1949 года в недостаточной степени отражают обычное право ${ }^{13}$.

Оппозицию ряда делегаций встретило на Спецкомитете предложение включить в ст. 20 , п. с проекта Статута ссылки на ст. 3, общую для Женевских конвенций 1949 года, и Дополнительный протокол II к ним, посвященные вооруженным конфликтам международного характера. При этом те, кто выступал за включение таких положений, обращали внимание на современную реальность вооруженных конфликтов, Устав Трибунала ad hoc для Руанды и решение Трибунала ad hoc для бывшей Югославии о признании общей ст. 3 Женевских конвенций в качестве обычно-правовой нормы ${ }^{14}$. Противники этого утверждали, что положения ст. 3 и Дополнительного протокола II в целом не являются частью обычного права и потому имеют обязательную силу лишь для государствучастников Конвенций и Протокола ${ }^{15}$.

Рассматривая преступления против человечности (ст. 20, п. $d$ проекта Статута), КМП исходила из того, что вопрос об определении этого преступления остается нерешенным. Вместе с тем имеется первоначальная формулировка преступлений против человечности, изложенная в ст. 6 с Устава Нюрнбергского трибунала, которая получила развитие в ст. 5 Устава Трибунала для бывшей Югославии. Основыва́ясь на имеющемся материале по данному вопросу, КМП пришла к заключению, что определение преступлений против человечности охватывает бесчеловечные деяния крайне тяжелого характера, включающие широко распространенные 
или систематические нарушения, направленные против гражданского населения в целом или какой-либо его части. Отличительной чертой таких преступлений является их широкомасштабный и систематический характер ${ }^{16}$.

Наибольшие споры на сессия Спецкомитета вызвали два вопроса, касающиеся этой группы преступлений.

Во-первых, это все тот же вопрос об определении преступлений против человечности. Было отмечено, что, несмотря на то что преступления против человечности отвечают критериям, позволяющим включить их в группу преступлений по общему международному праву, какой-либо конвенции, которая содержала бы общепризнанное и достаточно точное юридическое определение преступлений против человечности, не существует ${ }^{17}$.

Однако большинство делегаций основывались на том, что определения, содержашиеся в Уставах Нюрнбергского и Токийского трибуналов и трибуналов для бывшей Югославии и Руанды, создают достаточную основу для дальнейшей работы над определением.

При этом с учетом замечаний, содержашихся в докладе Спецкомитета, в будущем определении отразятся следующие элементы: преступления могут совершаться против любого гражданского населения, в отличие ог военных преступлений; эти преступления, как правило, сопряжены с широко распространенными и систематическими нападениями на гражданское население в отличие от изолированных правонарушений.

Во-вторых, это вопрос, касающийся того, должен ли перечень правонарушений, составляющих преступления против человечности, быть завершенным или он должен носить открытый характер.

Не было единства в Спецкомитете и по вопросу о том, могут ли преступления против человечности совершаться в мирное время в свете нюрнбергского прецедента, а также Устава Трибунала для бывшей Югославии ${ }^{18}$.

Выше уже говорилось о том, что так называемые «договорные преступления», очевидно, не войдут в сферу юрисдикции Суда. КМП исходила из того, что преступления, содержащиеся в договорах, определены таким образом, что Суд мог бы применять положения этих договоров в связи с конкретным преступлением с учетом гарантии принципа nullum crimen, nullum poena sine lege, содержащейся в ст. 39 проекта Статута. Кроме того, Комиссия учитывала, что каждый договор, содержащийся в проекте Статута, создает либо систему универсальной юрисдикции, основанную на принципе aut dedere aut јudicare, либо возможность разбирательства преступления в Международном уголовном суде, либо обе указанные возможности ${ }^{19}$.

Наряду с этим Комиссия пришпа к выводу о необходимости ограничения юрисдикции Суда в соответствии с договорами, пере- 
численными в Приложении, по той причине, что многие из этих договоров охватывают правонарушения, которые, хотя и являются серьезными сами по себе, полностью подиадают под юрисдикцию национальных судов, компетентных рассматривать такие правонарушения, и которые (в контексте конкретного дела) не требуют рассмотрения Международным уголовным судом. Это ограничение устанавливается в ст. 20, п.е проекта Статута, в соответствии с Которой требуется, чтобы данное преступление представляло собой исключительно серьезное преступление, вызывающее озабоченность у международного сообщества ${ }^{20}$.

Рядом членов КМП было подчеркнуто значение фактора систематичности совершения «договорных преступлений», особенно связанных с террористической деятельностью. Международное сообшество еще не разработало универсального определения терроризма, хотя в некоторых региональных конвенциях дается определение этого понятия. Кроме того, из 14 договоров, перечисленных в Приложении к Статуту, 6 касаются террористических преступлений (например, угона самолетов и взятия заложников). Таким образом, как подчеркнули ряд членов Комиссии, терроризм, когда он имеет систематический и постоянный характер, является преступлением, вызывающим озабоченность международного сообшества и охватываемым тем или иным из преступлений, указанных в ст. 20 проекта Статута. Кроме того, отмечалось, что терроризм, практикуемый в любой форме, универсально признан в качестве уголовного деяния ${ }^{21}$.

КМП псдчеркнула, что во многих случаях террористическая деятельность подкрепляется широкомасштабным бборотом наркотиков, несомненно вызывающим озабоченность у международного соббщества. В таких случаях требования ст. 20 , п.е относительно исключительно тяжкого характера преступления будут легко удовлетворяться ${ }^{22}$.

В ходе сессий Спецхомитета было высказано мнение, что правонарушения, указанные в договорах, могуг иметь меньший размах, чем другие правонарушения, предусмотренные в ст. 20, и что их включение в сферу юрисдикции Международного уголовного суда сопряжено с опасностью преврашения Суда, который должен концентрироваться на наиболее тяжких преступлениях, вызывающих озабоченность международного сообщества в целом, в обычное судебное учреждение. Кроме того, в пользу исключения рассматриваемых преступлений из сферы юрисдикции Суда был высказан аргумент о том, что указанные преступления более эффективно рассматриваются национальными судами. С конкретной ссылкой на терроризм и незаконный оборот наркотиков была выражена озабоченность в связи с тем, что распространение юрисдикиии Суда на эти преступления создаст для Суда чрезмерное бремя². 
В то же время делегация России в Спецкомитете выступала за сохранение в компетенции Суда террористических преступлений, вызывающих озабоченность мехдународного сообщества ${ }^{24}$.

Учитывая разногласия между государствами по вопросу о включении «договорных преступлений» в сферу юрисдикции Суда, российская делегация предложила, чтобы Суд рассматривал не все террористические преступления, а лишь те, которые создают угрозу миру и безопасности и, таким образом, вызывают озабоченность мирового сообщества в целом. В соответствии с положениями главы VII Устава ООН прерогатива определять наличие угрозы миру и безопасности принадлежит Совету Безопасности ООН. Таким образом, принятие Советом Безопасности, как в случае с «делом Локерби», резолюции, квалифицирующей то или иное террористическое преступление как создающее угрозу миру и безопасности, станет необходимым процедурным условием для задействования Советом механизма Суда, не имея при этом (как и в ситуации с агрессией) преюдициального значения.

КМП заложила в проект Статута две системы признания юрисдикции Суда. Первоначальный замысел Комиссии состоял в том, что юрисдикция Суда в отношении всего круга преступлений, упомянутых в ст. 20 проекта Статута, должна признаваться государствами автоматически на основании того, что государство становится участником Статута. Только в ряде случаев допускалась возможность неавтоматического (по заявлению государства о признании юрисдикции Суда в отношении конкретного преступления) признания юрисдикции Суда ${ }^{25}$.

Однако в дальнейшем Комиссия признала такой подход непродуктивным, и принятая в конечном итоге КМП система мохет быть в целом охарактеризована как неавтоматическая. В соответствии с ней юрисдикция в отношении большинства преступлений передается Суду посредством специального заявления, которое может быть сделано во время или после присоединения $\mathrm{K}$ Уставу ${ }^{26}$.

В «собственной» («inherent») юрисдикции Суда в проекте КМП осталось лишь преступление геноцида, в отношении которого признание юрисдикции Суда государством, согласно ст. 22 , не будет необходимым ${ }^{27}$.

В соответствии с неавтоматической системой в п. 1 ст. 22 проекта Статута предусматривается возможность для государств сделать общее заявление о признании юрисдикции Суда, что во многом сходно с положением ст. 36 Статута Международного Суда. Такое заявление может носить общий характер или иметь ограничения ratione materiae или ratione temporis. Такое заявление может быть сделано и в связи с конкретным делом ${ }^{28}$. 
После первой сессии Спецкомитета большинство государств сошлось во мнении, что, становясь участником Статута, каждое государство будет делать заявление о признании обязательной юрисдикции Суда в отношении тех или иных преступлений. Исключение, как и в проекте КМП, было сделано лишь для преступления геноцида. В отношении этого преступления Суд, по мнению большинства делегаций, долхен был обладать обязательной юрисдикцией, то есть достаточно жалобы любого государства - участника Статута и при соблюдении некоторых условий Суд может осуществлять свою юрисдикцию в отношении лиц, совершивших это преступление на территории другого государства - участника Статута, без специального признания им юрисдикции Суда в отношении геноцида $\mathrm{a}^{29}$.

Однако уже в ходе второй сессии Спецкомитета, после того как стало ясно, что к компетенции Суда будут отнесены лишь трипять преступлений по общему международному праву, все большее число делегаций стало высказываться в пользу того, что Суд будет осушествлять обязательную юрисдикцию в отношении всех преступлений, входящих в его компетенцию ${ }^{30}$.

Практически не вызвал разногласий в ходе сессий КМП и Спецкомитета вопрос о механизме задействования Суда. Дело может быть рассмотрено в Суде либо по заявлению (жалюбе) государства участника Статута, либо по решению Совета Безопасности ${ }^{31}$.

Делегации в Спецкомитете отвергли предложение предусмотреть в Статуте возможность рассмотрения дела по жалобам физических лиц ${ }^{32}$.

Важная роль в проекте Статута отводится Совету Безопасности ООН. Помимо прерогатив, которыми он обладает в случае агрессии (см. выше), в соответствии с положениями ст. 23, п. 1 проекта Статута, Совет Безопасности, действуя на основании главы VII Устава ООН, полномочен передавать дело на рассмотрение Суда. Это снимает вопрос о создании все новых и новых трибуналов ad hос. Такое право Совета Безопасности, вне зависимости от признания или непризнания тем или иным государством-участником Статута юрисдикции Суда, позволяет задействовать юрисдикцию Суда, когда этого требуют интересы мирового сообщества в целом (таким образом, и в этом случае Суд будет осушествлять обязательную юрисдикцию). При этом Совет Безопасности передает на рассмотрение Суда соответствуюшую ситуацию, а не вопрос об уголовной ответственности конкретных лиц ${ }^{33}$.

В соответствии со ст. 33 проекта Статута Суд применяет положения Устава, применимые договоры, принципы и нормы общего международного права и в применимой степени - любую норму внутригосударственного права. Таким образом, проект Статута недвусмысленно отдает предпочтение нормам международного пра- 
ва $^{34}$. В то же время последнее положение ст. 33 подверглось резкой критике в ходе работы сессий Спецкомитета. Многие государства сочли, что Суд должен применять не в применимой степени национальное право, а бпцие принципы права, внутригосударственное определение общих принципов права. При этом последние следует рассматривать как часть международного права ${ }^{35}$.

Что касается порядка учреждения Суда, то первоначально рассматривались два альтернативных варианта. Некоторые члены Комиссии считали, что Суд должен быть вспомогательньм органом ООН и учреждаться на основании резолюции Совета Безопасности и Генеральной Ассамблеи. Другие члены КМП настаивали на том, что Суд должен быть учрежден путем внесения поправок в Устав $\mathrm{OOH}^{36}$.

В конечном итоге в КМП возобладал иной подход, согласно которому Суд будет учрежден на основании международного договора ${ }^{37}$.

Подавляюшее большинство делегаций в Шестом комитете и на сессиях Спецкомитета высказались в пользу международного договора как единственного юридически приемлемого способа учреждения Суда ${ }^{38}$. Тахой способ, основанный на прямом и явно выраженном волеизъявлении государств, полностью соответствовал бы принципу суверенитета государств.

КМП и Спецкомитет сошлись во мнении относительно того, что между ООН и Судом должна существовать тесная взаимосвязь. Такая взаимосвязь будет установлена как путем внесения соответствующих положений в Статут Суда, так и путем заключения соответствуюшего договора между ООН и Судом ${ }^{39}$.

В заключение хотелось бы отметить, что на пути создания Суда стоит еше немало проблем. Среди них есть политические, прежде всего вопрос о предметной и юрисдикционной компетенции Суда, и юридико-технические, например целый ряд вопросов уголовно-правового характера (организация работы Суда, его правила процедуры и т.П.). И все же движение вперед налицо: государства не только пришли $\mathrm{x}$ пониманию необходимости создания постоянного Международного уголовного суда и приступили к практическому решению этой непростой задачи, но уже наметили основные параметры создаваемого института. А это значит, что сторонники идеи учреждения постоянного органа международной уголовной юстиции могут смотреть в будущее с определенным оптимизмом.

Р.А. Колодкин, заместитель директора Правового департамента МИД России, кандидат юридических наук И.А. Панин, aтташе Правового департамента МИД России, сонскатель кафедры мехдународного права МГИМО(У) МИД РФ. 
' Более подробно историю вопроса см.: Блищенко И.П., Фисенко И.В. Международный уголовный суд. - M., 1993 г.; Jules Deschenes, Toward International Criminal Justice, Criminal Law Forum, Vol. 5, 1994. Nov. 23. - P. 272-277, Satu Suikkari. Debate in the United Nations on the International Law Commissions. Draft Statute for an International Criminal Court/ /Nordic Journal of International Law. - 1995. - Vol. 64, No. 2. P. 205207.

${ }^{2}$ UN. Doc. GA, Res. 48/31 (1993).

3 Доклад Комиссии международного права о работе се 46-й сессии// UN. Doc. A/49/10 (1994).

${ }^{4}$ UN. Doc. GA Res. 49/53 (1995).

${ }^{5}$ UN. Doc. AVAC 244/CRP.6.

Ibid.

${ }^{7}$ Ibid.

8 lbid.

9 lbid.

${ }^{10}$ lbid.

1 UN. Doc. A/49/10 (1994) (комментарий к ст. 206).

${ }^{12}$ Tам же.

${ }^{13}$ UN. Doc. A/50/22, c. 1 , a (iii), p. $15-16$.

${ }^{14}$ Ibid.

${ }^{15}$ lbid.

${ }^{16}$ UN. Doc. A/49/10 (1994), p. 49.

17 UN. Doc. A/S0/22, c. 1 , a (iii), p. 17.

${ }^{18}$ Ibid.

${ }^{19}$ UN. Doc. A/49/10 (1994), p. 50.

${ }^{20}$ lbid.

${ }^{21}$ Ibid.

22 Ibid.

${ }^{23}$ UN. Doc. A/50/22, c. 1 , a(VI), p. 18.

${ }^{24}$ В декабре 1988 года в результате взрьва бомбы на самолете рейса 103 американской компании "Пан-Америкен» погибли 259 четовек и 11 жителей шотлаңдской деревни Локерби, на которую упали обломки самолета. Итоги расследования показали, что взрыв стал результатом террористнческого акта, совершенного двумя агентами ливийской разведки.

В резолюции 731 Совет Безопасности, исходя из того, что акты международного терроризма представляют собой угрозу международному миру и безопасности, потребовал от ливийского правительства представить ответы на запросы Франции, Великобритании и США, касанщнесх террористического акта, которьй произошел на борту самолета компании «Пан-Америкен». После того как данное требование Совет . Безопасности осталось без ответа, последовала резолюции 748 Совета Безопасности, в хоторой прямо указывалось, что Совет Безопасности налагает санхиии на Ливию, дсйствуя на основании своих полномочий по главе VII Устава ООН, касаюшихся мер, предпринимаемых при наличии угрозы международному миру и безопасности. Более подробно историю вопроса см., например, Блищенко И.П., Фисенко И.В., Указ. соч. - С. 93-102.

${ }^{25}$ UN. Doc. A/49/10 (1994), p. 54. 
${ }^{26}$ lbid., p. 53.

27 lbid., p. 54.

28 Ibid.

29 UN. Doc. AVAC 244/CRP.1/Add.2, at 1.

${ }^{30}$ UN. Doc. A/50/22, C. $2 a$, p. $20-23$.

31 Ibid.

${ }^{32}$ Ibid.

${ }^{33}$ Ibid.

${ }^{34}$ И.П. Блищенко и И.В. Фисенко в своей книге «Международный уголовный суд» отмечают, что положение, согласно которому Междугіродный утоловный суд может применять лишь международное право, которое одно может признавать определенные деяния в качестве международных преступлений, а применение национального права свидетельствует о том, что Суд является общим для некоторьх государств, но не международным, является в целом правильным.

${ }^{35}$ UN. Doc. A/49/10 (1994), p. 70.

${ }^{36}$ Дохлад Комиссии международного права о работе ее 42-й сессии (1990). - T. II, Часть $1, \S 7 .-$ - C. 102.

${ }^{37}$ UN. Doc. A/49/10 (1994), p. 24.

${ }^{38}$ UN. Doc. A/AC. 244/CRP. 1, p. 1; UN. Doc. A/50/22, II A 1 (15), p. $3-4$.

${ }^{39}$ UN. Doc. A/49/10 (1994), p. 24-25. UN. Doc. A/50/22. II A 1 (15), p. 4.

Cтатья поступила в редакцию в апреле 19962. 